\title{
ANTONIO CANDIDO E O ELOGIO DA LITERATURA
}

\section{ANTONIO CANDIDO AND THE PRAISE OF LITERATURE}

\author{
Marcos Falchero Falleiros ${ }^{1}$ \\ Universidade Federal do Rio Grande do Norte
}

\begin{abstract}
RESUMO
Tanto quanto Roland Barthes em O prazer do texto (1973) ou ainda em Aula (1977), Tzvetan Todorov em A literatura em perigo (2007) aparenta dedicar-se a uma espécie de recuo de seus vínculos e quiçá implicitamente apresentar um mea-culpa pelo papel preponderante que exerceu na implantação do estruturalismo na crítica literária - processo que causou uma tecnicização bastante funesta à fruição literária. Talvez mais que o sempre surpreendente e inquieto Barthes, Todorov pode ter causado com a publicação desse depoimento um saudável espanto em seus seguidores, ao alertar com irradiação retrospectiva que os andaimes para a construção de uma obra não podem substituí-la. Por outro lado, em palestra de 1988, no âmbito da discussão de direitos humanos, Antonio Candido não precisou passar pelos caminhos da presumida retratação ao falar sobre "O direito à literatura". Talvez acuado pela ditadura militar e pela imposição do estruturalismo no meio acadêmico das letras, que comodamente livrava estudiosos aderentes da abordagem de conteúdos históricos da literatura, o crítico brasileiro brincou ironicamente com o estruturalismo em "Dialética da malandragem" (1970), apresentando um daqueles bonitos diagramas da escola, cheios de setinhas, justamente para reverter seus pressupostos e ensinar que a estrutura literária da forma é histórica. Assim, no auge do processo de redemocratização do país, na referida palestra Antonio Candido enfatizou com plena autoridade a importância da literatura como instrumento de humanização imprescindível.
\end{abstract}

PALAVRAS-CHAVE: Antonio Candido; Literatura e humanismo; Forma literária e processo social; Estruturalismo histórico.

\begin{abstract}
Similar to Roland Barthes in The pleasure of the text (1973) or still in [Lesson] (1977), Tzvetan Todorov in [Literature in peril] (2007) seems to devote to a sort of retreat of its links and perhaps implicitly present a mea-culpa by the preponderant role that he played in the implantation of structuralism in literary criticism - a process that caused a quite fatal technicalization to the literary fruition. Perhaps more than the ever-surprising and restless Barthes, Todorov may have caused the publication of this testimony to be a good surprise to his followers by warning with hindsight that scaffolding for the construction of a work can not replace it. On the other hand, in a lecture in 1988, in the scope of the discussion of human rights, Antonio Candido did not have to go through the paths of presumed retraction when talking about "The right to literature". Perhaps as a result of the military dictatorship and the imposition of structuralism in the academic medium of letters, which comfortably freed adherent scholars from the historical content of literature, the Brazilian critic played ironically with structuralism in "Dialectic of malandroism" (1970), presenting one of those beautiful diagrams of its methodology, full of arrows, just to reverse its assumptions and teach that the literary structure of the form is
\end{abstract}

\footnotetext{
${ }^{1}$ Doutor em Literatura Brasileira pela Universidade de São Paulo. Professor de Literatura Brasileira e Literatura Comparada da Universidade Federal do Rio Grande do Norte - UFRN. E-mail: marcffal@gmail.com
} 
historical. Thus, at the height of the country's redemocratization process, Antonio Candido emphasized with full authority the importance of literature as an essential humanization tool.

KEYWORDS: Antonio Candido; Literature and humanism; Literary form and social process; Historical structuralism.

\title{
INTRODUÇÃO
}

Entre o cediço e o rebelado, O pražer do texto, em 1973, e, cinco anos depois, Aula, em 1977, foram as intervenções de Barthes que propagaram filigranados ares novos àquela década de esquemas - duas intervenções em uníssono, sustentadas pelo ensinamento de Nietzsche em seu \ 192 de Para além do bem e do mal:

\begin{abstract}
Quem tem acompanhado a história de uma determinada ciência encontra no seu desenvolvimento um fio condutor para compreender os processos mais antigos e mais comuns de todo "saber e conhecer": em um e em outro caso, a primeira coisa que se desenvolveu foram as hipóteses precipitadas, as fabulações, a boa e estúpida vontade de "crer", a falta de desconfiança e de paciência - os nossos sentidos aprendem muito tarde, e nunca de todo, a ser órgãos de conhecimento sutis, fiéis, cautelosos. A nossos olhos, torna-se mais cômodo voltar a produzir, a cada ocasião, uma imagem produzida já muitas vezes do que reter dentro de si os elementos divergentes e novos de uma impressão: estes últimos exigem mais força, mais "moralidade". (NIETZSCHE, 1972, p. 121).
\end{abstract}

À geometria em linhas límpidas de um racionalismo ressecado por grades, setas, diagramas e quadros de relações, o semiólogo francês respondia, do lado de dentro da temporada estruturalista, com a lição de verdade proposta por Nietzsche:

\begin{abstract}
do mesmo modo, tampouco veremos uma árvore de uma forma rigorosa e completa em relação a suas folhas, ramos, cor, figura; consideramos muito mais fácil fantasiar uma aproximação da árvore. Continuamos agindo assim mesmo em meio às experiências mais incomuns: a maior parte das experiências, nós a imaginamos com a fantasia, e dificilmente forçamo-nos a não contemplar qualquer processo como "inventores". Tudo isso quer dizer: na raiz, desde os tempos antigos, estamos habituados a mentir. (1972, p. 122)2.
\end{abstract}

As palavras de Barthes em O praz̧er do texto confirmavam que a "fabulação" e a "invenção", mencionadas por Nietzsche como sinônimos de "mentir", não têm nada de fantasia inventiva e têm tudo de repetitiva "redução":
A árvore é a cada instante uma coisa nova; nós afirmamos a forma porque não apreendemos a sutileza de um movimento absoluto (Nietzsche).
O texto seria também essa árvore cuja nomeação (provisória) devemos ao caráter grosseiro de nossos órgãos. Nós seríamos científicos por falta de sutileza. (BARTHES, 1987, p. 78).

Contra o científico e a favor da sutileza, ele retomaria a observação dali a alguns poucos anos, para concluí-la, em Aula, contrapondo, à ciência grosseira, a vida sutil - uma distância de antípodas que a literatura tem por finalidade corrigir (1987, p. 18). Compagnon certamente alude a passagens como essa, ao percorrer em seu percurso histórico o currículo dos dilemas da crítica universitária francesa sobrepostos à literatura com confrontações entre tendências e

\footnotetext{
${ }^{2}$ Estão traduzidos para o português os trechos de edições em língua estrangeira citados neste texto.
} 
metodologias. É o que transparece quando o crítico avalia a quadro de esvaziamento das falsas questões que o século deixou evidente:

No final do século XX, a velha disputa da história e da teoria, ou da filologia e da retórica, variante tardia da Querela dos Antigos e dos Modernos, enfim não mais teve razão de ser. Roland Barthes, que por muito tempo desconfiara da emoção e do valor, voltou a eles em sua aulas no Collège de France e em seus últimos livros. (COMPAGNON, 2009, p. 18).

Com esse diagnóstico, o estudioso francês de nova geração prepara o argumento da justificativa de seu posicionamento, cujo conteúdo soaria como um aprendizado de antigas lições de Antonio Candido não fosse suficiente a obviedade do bom senso para alcançá-las:

\begin{abstract}
Sem desconhecer a tensão secular entre criação e história, entre texto e contexto ou entre autor e leitor, por minha vez, proporei aqui sua conjunção, indispensável ao bemestar do estudo literário. Talvez porque eu tenha vindo a este inocentemente e por vias insólitas, sempre resisti a esses dilemas impostos e recusei as exclusões mútuas que pareciam fatais à maior parte de meus contemporâneos. O estudo literário deve e pode consertar a fratura da forma e do sentido, a inimizade factícia da poética e das humanidades. (COMPAGNON, 2009, p. 18).
\end{abstract}

Sob outra perspectiva, muito tempo depois de Barthes, à maneira de um balanço rememorativo em 2007, Tzvetan Todorov (2010) sentiu necessidade de negar ${ }^{3}$ que se tratava de um mea-culpa o grito de alerta, atrasado mas regenerador, de seu $A$ literatura em perigo. Mais que o inquieto Barthes, Todorov, com a publicação desse depoimento, pode ter causado espanto aos leitores de seus primeiros estudos, ao advertir, com irradiação retroativa, que os andaimes para a construção de uma obra não podem substituí-la e devem desaparecer como os de um prédio após sua construção (TODOROV, 2010, p. 32). Com isso o autor criava uma imagem próxima de uma limpeza dupla: primeiramente referida ao resultado da obra, afastando os possíveis bastidores metalinguísticos de sua elaboração, para então repelir, em nome da fruição da arte, a arqueologia que buscasse restaurá-los como objetivo final de sua razão de ser.

O crítico búlgaro, que se radicou na França como um dos principais teóricos responsáveis pela análise estruturalista da literatura, não descarta, entretanto, a qualidade do método a que aderiu nas décadas precedentes ao século de onde agora fala, mas pondera que as então bemvindas inovações da abordagem estrutural deveriam ter se limitado a meros instrumentos de aproximação e leitura, para não se transformarem numa finalidade fechada sobre si mesma. Lamenta que a prevalência conquistada pela abordagem estruturalista tenha acuado a literatura na sua essência, em sua relação com a vida, e enxerga no século XXI um quadro deplorável, em que o ponto fundamental foi esquecido: "Nós - especialistas, críticos literários, professores - não somos, na maior parte do tempo, mais do que anões sentados em ombros de gigantes" (TODOROV, 2010, p. 31).

O esquecimento dessa condição leva à concepção redutora da literatura, que domina salas de aula de ensino médio, cursos universitários, a teoria e a crítica literária, o jornalismo de resenhas. A mutilação do texto como pretexto para aplicações teóricas dilapida e negligencia a

\footnotetext{
3 “Todorov diz que La littérature en péril não é um 'mea culpa', mas que se sente 'um pouco responsável' pela situação atual." - conforme artigo de Justo Barranco, do jornal on-line La vanguardia, Barcelona, com tradução de Luiz Roberto Mendes Gonçalves: "O assassinato da literatura, segundo Todorov. Tzvetan Todorov lamenta a concepção redutora das letras nas escolas, crítica e autores". Disponível em:

$<$ educacao.uol.com.br/noticias/2008/02/14/la-vanguardia-o-assassinato-da-literatura-segundo-todorov.htm? > . Acesso em: 12 set. 2016.

Original em espanhol, com acesso de 27 mar. 2017, disponível em:

$<$ hemeroteca-paginas.lavanguardia.com/LVE05/PUB/2007/12/03/LVG200712030431LB.pdf >.
} 
totalidade da obra em sua significação humanística referenciada para o mundo e transforma a literatura no jogo de seus elementos constitutivos. E como não poderia deixar de acontecer, por força do círculo vicioso, a contaminação atinge a fonte, e os criadores passam a escrever para a crítica especializada:

Numerosas obras contemporâneas ilustram essa concepção formalista da literatura; elas cultivam a construção engenhosa, os processos mecânicos de engendramento do texto, as simetrias, os ecos e os pequenos sinais cúmplices. (TODOROV, 2010, p. 42).

Tão nefasto quanto o amaneiramento experimental, será o deboche negativista, dividido entre o niilismo e o solipsismo. Este último "leva o autor a descrever detalhadamente suas menores emoções, suas mais insignificantes experiências sexuais, suas reminiscências mais fúteis: quanto mais repugnante, mais fascinante é o mundo!” (TODOROV 2010, p. 43). E assim o quadro se fecha:

\begin{abstract}
Niilismo e solipsismo mais completam a escolha formalista do que a refutam: a cada vez, mas a partir de modalidades diferentes, é o mundo exterior, o mundo comum a mim e aos outros, que é negado e depreciado. É devido a isso que, em grande parte, a criação contemporânea francesa é solidária da ideia da literatura que se pode encontrar na base do ensino e da crítica: uma ideia absurdamente restrita e empobrecida. (2010, p. 44).
\end{abstract}

\title{
1. Tempos
}

Terry Eagleton observa os tempos recentes e avalia ironicamente as novidades: "Antes os alunos escreviam ensaios acríticos reverenciosos sobre Flaubert; mas tudo isso mudou. $\mathrm{Na}$ atualidade escrevem ensaios acríticos reverenciosos sobre a série Friends" (2005, p. 17). Eis o tempo em que Alfredo Bosi deverá espantar-se com a pergunta "A poesia é ainda necessária?", quando foi encarregado de respondê-la para uma aula inaugural": "Leitor de poemas desde os anos da adolescência, nunca pensaria que devesse, um dia, falar da necessidade da poesia. $\mathrm{O}$ tema proposto talvez seja mais um sinal dos tempos" (BOSI, 2013, p. 9). Bosi se vale da formulação de Heidegger sobre a linguagem-poesia como a "casa do Ser" para sugerir que a expressão de alcance ontológico se estenda para o plano existencial: "a linguagem permite que as coisas ganhem um sentido público e comunicável na teia intersubjetiva” (2013, p. 9). A poesia dá humanidade ao anonimato da massa amorfa que se arrasta pelo mundo desencantado, como ocorre na explosão final da vida a que chega o desfilar funéreo de Morte e vida severina, um "Auto de Natal pernambucano", de João Cabral de Melo Neto.

A aula inaugural de Bosi registra subtítulos como "O que era sombra errante vira gente" e, por último, "O belo como catarse", quando o mestre finaliza sua fala com uma citação extraída do Zibaldone di pensieri de Leopardi, que pode ser lida à guisa de glosa da epígrafe em seu texto, o verso de Shakespeare, "And, Beanty dead, black Chaos comes again", de Venus and Adonis (BOSI, 2013, p. 9):

Têm de particular as obras de gênio que, mesmo quando representem ao vivo o nada das coisas, mesmo quando demonstrem evidentemente e façam sentir a inevitável infelicidade, mesmo quando exprimam os desesperos mais terríveis, todavia para uma alma grande que se encontre também em estado de extremo abatimento, desengano, nulidade, tédio e desencorajamento da vida, servem de consolação, reacendem o entusiasmo, e não tratando nem representando outra coisa que não a morte, lhe

\footnotetext{
4 “Aula inaugural da Cátedra de Estudos Irlandeses W. B. Yeats, Faculdade de Filosofia, Letras e Ciências Humanas da USP, março de 2010” (BOSI, 2013, p. 473).

5 Traduzível por: "E morta a Beleza, o negro Caos vem de novo".
} 
devolvem ao menos por um momento aquela vida que ela havia perdido. E assim aquilo que, visto na realidade das coisas, confrange o coração e mata a alma, visto na imitação, ou de qualquer outro modo, nas obras de gênio (como, por exemplo, na lírica, que não é propriamente imitação), abre o coração e o reaviva. (1949 apud BOSI, 2013, p. 23).

Mas não apenas os tempos recentes revelam com o desprezo à literatura a sua falta de educação. Sem lembrar-se da cômica figura das histórias em quadrinhos de Goscinny e Uderzo, o bardo Chatotorix cujo canto é considerado intragável pela aldeia do gaulês Asterix, Nuccio Ordine apresenta em $A$ utilidade do inútil um amplo panorama de passagens de grandes autores por ele colecionadas com o objetivo de refletir sobre a noção de utilidade e, nisto, sua aplicação à literatura, vista tradicionalmente como inútil. Uma inutilidade sob a acusação agravante de ser perniciosa - tal perseguição é historiada por Antonio Candido (1987) com minuciosa erudição em seu ensaio "Timidez do romance", recuando até o Renascimento para apresentar o percurso e as vicissitudes desta dramática reputação, sob as argumentações pró e contra em que pelo correr dos séculos apareceu posta na berlinda a sempre suspeita "literatura de imaginação":

Isto faz que a literatura quase nunca tenha consciência tranquila e manifeste
instabilidades e dilaceramentos, como tudo que é reprimido ou contestado: tem dramas
morais, renuncia, agride, exagera a própria dignidade, bate no peito e se justifica sem
parar. Não é raro ver os escritores envergonhados do que fazem, como se estivessem
praticando um ato reprovável ou desertando de função mais digna. Então, enxertam na
sua obra um máximo de não-literatura, sobrecarregam-na de moral ou política, de
religião ou sociologia, pensando justificá-la deste modo, não apenas ante os tribunais da
opinião pública, mas ante os tribunais interiores da própria consciência. (CANDIDO,
1987, p. 82-83).

Ordine aborda também os diálogos de Platão, teatro transformado em teoria, mas ao referir-se apenas à discussão do Teeteto e do saber desinteressado, fica sem mencionar a "velha divergência" (VILLELA-PETIT, 2003, p. 52) entre poesia e filosofia, reacesa pela recomendação famosa de $A$ república para que se expulsem os poetas da cidade, sob o diagnóstico platônico de que a poeisis, a literatura, a imitação, tendo por essência o feito, o inventado (sendo razoável incluir no conjunto o lirismo), é uma verdade literalmente ficcional, nefasta à justiça, porque o poeta, o fazedor, essencialmente e etimologicamente deturpa a verdade com fabricar o real. Bosi rebate diagnóstico e prognóstico platônicos ao propor em $O$ ser e o tempo da poesia a poesiaresistência como arma de combate à condição do poeta expulso da república, condição já dada pelo andar dos séculos como "um fato íntimo e insuperado" (1977, p. 149):

Do Romantismo ao Surrealismo desfilam protestos do Imaginário contra o prestígio tirânico da Consciência racional ou prática. São as várias poéticas do Inconsciente, do sonho e dos sentidos, que se esforçam por mudar em penhor de glória a acusação movida por Platão à arte como perturbadora da polis. (1977, p. 209).

Por sua vez, Nuccio Ordine encontra a velha sina em Baudelaire e seu poeta-albatroz, príncipe das nuvens reduzido à irrisão das enormes asas desajeitadas ao pousar no chão pedestre de um barco, quando assim o portentoso pássaro é acuado pelo bullying de marinheiros boçais. $\mathrm{Na}$ tradução metricamente trabalhada de Ivan Junqueira (BAUDELAIRE, 2002, p. 107-108), "O albatroz":

Às vezes, por prazer, os homens da equipagem

Pegam um albatroz, imensa ave dos mares,

Que acompanha, indolente parceiro de viagem,

O navio a singrar por glaucos patamares. 
Tão logo o estendem sobre as tábuas do convés,

O monarca do azul, canhestro e envergonhado, Deixa pender, qual par de remos junto aos pés, As asas em que fulge um branco imaculado.

Antes tão belo, como é feio na desgraça Esse viajante agora flácido e acanhado! Um, com o cachimbo, lhe enche o bico de fumaça, Outro, a coxear, imita o enfermo outrora alado!

O Poeta se compara ao príncipe da altura Que enfrenta os vendavais e ri da seta no ar; Exilado no chão, em meio à turba obscura, As asas de gigante impedem-no de andar. ${ }^{6}$

Ordine também lembra a amargura irônica do Flaubert de Madame Bovary, em seu Dicionário de ideias feitas, que define a poesia como inútil, fora de moda, e o poeta, como bobo sonhador. Mas frisa a grande ressalva de Hölderlin que não deve ser esquecida (ORDINE, 2016, p. 10), coincidindo com as palavras finais de Bosi em "Fora sem dentro?" (ensaio mencionado em sua aula acima referida), uma leitura de "Festa na casa-grande", onde o crítico brasileiro encontra nas marcas ideológicas das vozes dos poemas mais que a objetividade múltipla da superfície, como se poderia esperar da estética professada por João Cabral de Melo Neto: "nem toda poética explícita esgota a poesia assim como nem toda retórica dá conta da eloquência. ' $\mathrm{O}$ que resta', diz Hölderlin, 'fundam-no os poetas"' (BOSI, 2013, p. 56).

\footnotetext{
6 Segue o original, "L'albatros" (BAUDELAIRE, 1999, p. 7), acompanhado, para não usuários de francês, de tradução literal e indicação de pronúncia aproximada:

Souvent, pour s'amuser, les hommes d'équipage [Sempre, para se divertir, os homens da tripulação] [Suvã pursamusê lesôme dequipage ]

Prennent des albatros, vastes oiseaux des mers, [Pegam os albatrozes, vastos pássaros dos mares,] [Prêne lesobatrô vaste oasô demér]

Qui suivent, indolents compagnons de voyage,

[Que seguem, indolentes companheiros de viagem,]

[Quissiive andolã companhõ devoiage ]

Le navire glissant sur les gouffres amers.

[O navio deslizante sobre os abismos amargos.]

[Lenavirri glissã sur legufre amér ]

A peine les ont-ils déposés sur les planches, [Apenas os têm eles posto sobre as pranchas,] [Apéne lesontíle deposê sir leplanche]

Que ces rois de l'azur, maladroits et honteux, [Que estes reis do azul, desajeitados e vergonhosos,]

[Quecerruá delazir maladruáze eontê ]

Laissent piteusement leurs grandes ailes blanches [Deixam pateticamente suas grandes asas brancas]

[Lésse pitêseman lér grande éle blanche ]

Comme des avirons traîner à côte d'eux.

[Como remos se arrastar ao lado deles.]

[Come desavirrõ trenê acotedê ]
} 


\section{Antonio Candido sem desculpas}

Antonio Candido não precisou passar pelos caminhos da presumida retratação ao falar sobre "O direito à literatura" (CANDIDO, 2011). Acuado pela ditadura militar, sintomaticamente contemporânea da imposição do estruturalismo no meio acadêmico das letras, restava ao crítico brasileiro resistir aos ditames intransigentes dos estudiosos aderentes à metodologia que os livrava com cômoda facilidade da imprudente abordagem de conteúdos históricos da literatura. Estes reivindicavam a interpretação da obra estética "em termos rigorosamente estéticos", contra os "pseudo-doutrinadores" que, sob uma "dialética falsa", pretendiam "ver, na criação artística, mero epifenômeno das ciências sociais":

Urge que se dê caça a essa mentalidade deformadora, desmascarando-a sob todos os disfarces em que se oculte, pois é inadmissível que, na atualidade dos acontecimentos culturais, tal orientação ainda prossiga constituindo obstáculo ao devassamento daquelas construções, que não se isolam, em hipótese nenhuma, mas que só se sustentam de fato pelos seus valores específicos. (MOURÃO, 1969, p. 16).

Sob esse prisma, a obra crítica de Antonio Candido mostrava-se passível de alguma censura, por exemplo, no caso de sua análise e interpretação da obra de Graciliano Ramos, enfeixada em Fiç̧ão e confissão, onde são apontados obstáculos "entre o crítico e a obra" como o "travo impressionista" de muitas de suas formulações e a perda do "chão firme da literatura" graças a escorregadas para o "plano da psicologia e da sociologia":

O estudo isolado de cada um dos romances chega a resultados excelentes e constitui o ponto alto da crítica sobre o autor de Caetés. Isso se deve, porém, mais a prodígios de bom gosto e intuição do que à validade do método empregado. Ora mais, ora menos visível, o sociologismo é uma malha de que Antonio Candido não consegue se libertar e que se trai até mesmo pelas expressões usadas: "sentimento patriarcal" [...] "peças de engrenagem rural" [...] "resultado mecânico de certas relações econômicas" etc. (MOUR ÃO, 1969, p. 12).

Daí, no auge repressivo da ditadura militar no Brasil, Antonio Candido enfrentou os arrochos da época brincando ironicamente com o estruturalismo em "Dialética da malandragem" (1970), com um daqueles bonitos diagramas da escola, cheios de setinhas (suprimido depois nas novas edições) ${ }^{7}$ justamente para reverter seus pressupostos e ensinar que a estrutura literária da forma é histórica.

Sobre a importância fundadora desse ensaio, Roberto Schwarz apresentaria ao mestre, com "Pressupostos, salvo engano, de 'Dialética da malandragem", a homenagem vigorosa, destoante do ambiente acadêmico vezeiro de salamaleques laudatórios: um ensaio sobre o grande ensaio, numa parceria feita de exegese minuciosa e franca discussão, que se anexa definitivamente ao ensaio-alicerce e de cuja leitura refletida e exaustiva extrai a outra face da mesma moeda dialética. Ao reverenciar o método que no vaivém entre ficção e realidade dá prioridade absoluta à forma literária, Schwarz nota a raridade de sua contraposição exemplar à usual escassez de confiança no valor de conhecimento da arte, o que faz de "Dialética da malandragem" um ensaio

\footnotetext{
7 O minucioso gráfico da dialética de ordem e desordem, que apresenta uma espécie de organograma dos personagens de Memórias de um sargento de milícias em seu movimento dinâmico de allegro vivace (ver reprodução do diagrama na apresentação desta coletânea) encontra-se atualmente disponível apenas na edição original do ensaio, entre as páginas 78-79, na Revista do Instituto de Estudos Brasileiros, IEB-USP, n. 8, 1970, p. 67-89:< revistas.usp.br/rieb/article/ view/69638 >. Acesso em 06 jan. 2013. Posteriormente, na publicação definitiva em livro, em O discurso e a cidade (CANDIDO, 1998, p. 45), o autor manteve apenas um gráfico de menor proporção para indicar a relação entre os dados particulares do real e o mundo fictício.

8 Publicado originalmente no volume de homenagem a Antonio Candido, Esboço de figura, São Paulo: Duas Cidades, 1979, com organização de Celso Lafer (SCHWARZ, 1987, p. 180).
} 
sem precedentes no Brasil e posto na melhor companhia mundo afora (SCHWARZ, 1987, p. 140-141):

\begin{abstract}
Sem ostentação de terminologia, e com notável liberdade de método, o Autor se volta para o interesse literário tal como a vida o põe: o que me diz este livro hoje? Se na fase de furor terminológico, inaugurada por Afrânio Coutinho, a finalidade da literatura de ensaio esteve em documentar atualização científica, parece que agora ela volta à vocação interpretativa, que é o seu interesse verdadeiro e extrauniversitário. (SCHWARZ, 1987, p. 154-155).
\end{abstract}

O equilíbrio e a uniformidade da visão da literatura de Antonio Candido adiantava-se, sem a necessidade de corrigir rumos, aos grandes nomes da crítica europeia. Antecipado, prenunciando Barthes e muito antes de Todorov, o crítico brasileiro não precisou das firulas bizantinas do pós-modernismo de uma civilização cansada para espantar-se com Essa estranha instituição chamada literatura e para constatar com Derrida que a literatura pode "dizer tudo" (DERRIDA, 2014). Pelo contrário, desde o início de suas atividades intelectuais, Antonio Candido vinha propondo a "crítica integrativa", que pode ser apreciada, para usarmos os termos acima citados, como notável liberdade de método no que diz respeito à percepção da literatura na totalidade de sua relação entre forma literária e processo social. Ou, nos termos em que o próprio crítico reiterava sua argumentação no prefácio à $2^{\mathrm{a}}$. edição, em 1961, de sua tese de 1945 sobre Sílvio Romero e o método crítico:

Sílvio achincalhava o que lhe parecesse 'esteticismo'; muitos dos críticos atuais repelem (de boca) o recurso a qualquer 'fator externo'. Em ambos os casos, posições parciais, apresentadas com a mesma imodéstia, deformando a inteligência plena do fenômeno literário. (CANDIDO, 1988, p. 14).

Assim, em palestra de 1988, no âmbito da discussão de direitos humanos e da consolidação do processo de redemocratização do país, enfatizou com plena autoridade a importância da literatura como instrumento imprescindível de humanização. Incumbido de complementar com Literatura as reticências do título aberto Direitos humanos e..., participou do ciclo de palestras sob tal tema promovido pela Comissão de Justiça e Paz da Arquidiocese de São Paulo (FESTER, 1989). O assunto que lhe coube, como avisa em sua apresentação no texto daí resultante, "O direito à literatura" (CANDIDO, 2011, p. 171), aparentemente meio desligado dos problemas reais, impõe ao autor um introito que aborde o tema geral dos direitos humanos como valor necessário a nossos tempos, marcados pela espantosa contradição entre um máximo de promissora racionalidade técnica e a irracionalidade de uma bárbarie galopante, ainda que esta se mantenha hipocritamente acuada:

Todos sabemos que a nossa época é profundamente bárbara, embora se trate de uma barbárie ligada ao máximo de civilização.

$[\ldots]$

\footnotetext{
${ }^{9}$ A respeito de sua metodologia aberta, Antonio Candido diz em entrevista a Gilberto Velho e Yonne Leite: “eu me pus a fazer aquelas misturas que constituem o meu modo de tentar a maior amplitude possível e evitar os dogmatismos, sem perder o prumo. Este prumo eu encontrei sobretudo na noção de estrutura, ligada às de processo e de montagem, como termos de uma visão integrada. Mas acima das posições teóricas, me parecem fundamentais a confiança na intuição e o desejo de correlacionar. Para uso próprio chamo a minha posição crítica de 'integrativa', procurando fundir perspectivas diferentes para obter um resultado mais completo. E sempre tive o gosto de pensar em função dos contrários". Disponível em: < canalciencia.ibict.br/notaveis/livros/antonio_candido_14.html >. Acesso em: 06 jan. 2013. Leopoldo Waizbort (2007) revelou a convergência entre Candido e Auerbach no espírito aberto à metodologia e na valorização de uma percepção mediada entre os aspectos que de saída o subtítulo de seu trabalho já destaca: crítica literária, sociologia, filologia.
} 


\begin{abstract}
Mas esta verificação desalentadora deve ser compensada por outra, mais otimista: nós sabemos que hoje os meios materiais necessários para nos aproximarmos desse estágio melhor existem, e que muito do que era simples utopia se tornou possibilidade real.
\end{abstract}

\title{
$[\ldots]$
}

Quem acredita nos direitos humanos procura transformar a possibilidade teórica em realidade, empenhando-se em fazer coincidir uma com a outra. Inversamente, um traço sinistro do nosso tempo é saber que é possível a solução de tantos problemas e, no entanto, não se empenhar nela. Mas de qualquer modo, no meio da situação atroz em que vivemos há perspectivas animadoras. (CANDIDO, 2011, p. 172).

São observações que suscitam a lembrança das reflexões de Hanna Arendt em Origens do totalitarismo, quando a autora equaciona fases do percurso humano: no século XVIII, o homem emancipou-se da história, e, no século XX, da natureza, para alcançar a pura "humanidade" donade-si nos tempos modernos, momento em que o "direito de ter direitos, ou o direito de cada indivíduo de pertencer à humanidade" seria garantido pela própria humanidade. Entretanto, a observação desses tempos desperta prognósticos sinistros que a fazem considerar o recado esquecido de Platão de que "não o homem, mas um deus, deve ser a medida de todas as coisas" (ARENDT, 2012, p. 259-260).

A percepção benfazeja de Antonio Candido, menos sombria, aposta mais na humanidade e na consciência de seu novo estatuto do "direito de ter direitos". Para discutir o assunto específico de sua palestra, recorre a uma distinção elaborada por Louis-Joseph Lebret, entre "bens compressíveis" e "bens incompressíveis" (CANDIDO, 2011, p. 175), terminologia vinculada à ideia de "compressão" no sentido do que pode ou não ser limitado e eliminado como supérfluo do quadro das necessidades humanas e seus direitos. A conceituação naquele momento imantava a música popular coetânea, cuja letra, na mesma direção do argumento de Candido, proclamava, em linguagem mais direta, que as pessoas não queriam só comida, mas também arte.

\section{Atestado de antecedentes}

Num texto sensível, em tom de crônica e memorialismo, "A literatura como direito" (LOPEZ, 2009), ainda que projetado sobre a totalidade atual da coletânea Vários escritos, Telê Ancona Lopez centra-se em "O direito à literatura". Daí permite que se perceba a condição nuclear desse ensaio numa dimensão expansiva tal, que não se limita apenas ao conjunto daquele volume, mesmo porque sua publicação ali ocorreu só depois, quando as edições sucessivas do título foram substancialmente aumentadas. Assim, ao intitular seu texto com o eco especular do quiasmo, potencializando a sugestiva significação fechada de um direito incontornável, entre " $O$ direito à literatura" e "A literatura como direito", a autora historia a linha de coerência do mestre, reforçando o argumento com a indicação de um ensaio anterior, raiz daquele, também proveniente de uma palestra, nesse caso na SPBC de 1972, grande evento histórico de resistência à ditadura militar que oprimia o pensamento no Brasil: "A literatura e a formação do homem" (CANDIDO, 2002). Nessa palestra, iluminando o período de trevas, o crítico, mais uma vez, com a insistência paciente de um grande mestre, desmonta preconceitos de classe e segregações entre estética e história para afirmar a literatura como fundamental, vista sob a amplitude de todos os ângulos da condição humana: 
inteligência da estrutura depende em grande parte de se saber como o texto se forma a partir do contexto, até constituir uma independência dependente (se for permitido o jogo de palavras).

\section{$[\cdots]$}

Tendo assim demarcado os campos, vejamos alguma coisa sobre a literatura como força humanizadora, não como sistema de obras. Como algo que exprime o homem e depois atua na própria formação do homem. (CANDIDO, 2002, p. 79-80).

\section{CONCLUSÃO}

Na homenagem acima referida, Telê Ancona Lopez (2009) chama a atenção para o pórtico de Vários escritos, muitas vezes despercebido, embora presente desde suas primeiras edições. Trata-se da epígrafe que recebe o leitor, vinda de Alice no país das maravilhas: "what is the use of a book, thought Alice, without pictures or conversations?"10 (CANDIDO, 2011, p. 11). Se inicialmente a epígrafe tinha por função aparente avisar o leitor dos assuntos variados que, entre registros de conversas e memórias de cenas, a obra ensaística coligia, por outro lado, de modo mais essencial, revela agora o recado do autor afinal desvendado no ensaio que inaugura a segunda parte das novas edições, naquele sentido em que "O direito à literatura" é qualificado pela pesquisadora:

Norteado por ideias de cunho socialista, Antonio Candido recorre ao seu cabedal de teórico e crítico para expor a função humanizadora da literatura, diretamente vinculada à satisfação de uma necessidade incontestável do ser humano, cravada na psique de todos nós - o sonho, a efabulação que transfiguram a vida na criação literária. (LOPEZ, 2009, p. 218).

\section{REFERÊNCIAS BIBLIOGRÁFICAS}

ARENDT, Hanna. Origens do totalitarismo. Tradução Roberto Raposo. São Paulo : Companhia das Letras, 2012.

BARTHES, Roland. Aula. Tradução Leyla Perrone-Moisés. 14. ed. São Paulo: Cultrix, 1980. O pražer do texto. Tradução Jacob Guinsburg. São Paulo: Perspectiva, 1987. (Elos, 2).

BAUDELAIRE, Charles. EEuvres complètes. Notices et notes de Michel Jamet. Préface de Claude Roy. Paris: Robert Laffont, 1999. (Bouquins).

- Poesia e prosa. Organização, revisão e notas adicionais de Ivo Barroso. Rio de Janeiro: Nova Aguilar, 2002.

BOSI, Alfredo. Entre a literatura e a história. São Paulo: Ed 34, 2013. O ser e o tempo da poesia. São Paulo: Cultrix, 1977.

CANDIDO, Antonio. A educação pela noite. São Paulo: Ática, 1987.

\footnotetext{
${ }^{10}$ Em português: “e de que serve um livro, pensou Alice, sem figuras nem diálogos?” (CARROLL, 2009, p. 13).
} 
A literatura e a formação do homem. In:

Textos de intervenção. Seleção, apresentação e notas de Vinicius Dantas. São Paulo: Duas Cidades; Ed. 34, 2002, p. 77-92.

. Dialética da malandragem. Revista do Instituto de Estudos Brasileiros, n. 8, p. 67-89. São Paulo: Universidade de São Paulo, 1970.

. O discurso e a cidade. São Paulo: Duas Cidades, 1998.

. O método crítico de Sílvio Romero. 3 ed. São Paulo: Edusp, 1988.

. Vários escritos. 5. ed. corrigida pelo autor. Rio de Janeiro: Ouro sobre Azul, 2011.

CARrolL, Lewis. As aventuras de Alice no País das Maravilhas \& Através do espelho e o que Alice encontrou por lá. Tradução Maria Luiza X. de A. Borges. Rio de Janeiro: Zahar, 2009.

COMPAGNON, Antoine. Literatura para quê? Tradução Laura Taddei Brandini. Belo Horizonte: Editora UFMG, 2009.

DERRIDA, Jacques, Essa estranba instituição chamada literatura: uma entrevista com Jacques Derrida. Edição de Evandro Nascimento. Tradução Marileide Dias Esqueda. Belo Horizonte: Editora UFMG, 2014.

EAGLETON, Terry. Después de la teoría. Trad. de Ricardo García Pérez. Barcelona: Randon House Mondadori, 2005.

FESTER, Antonio Carlos Ribeiro (org.). Direitos bumanos e... . São Paulo: Brasiliense; Comissão de Justiça e Paz de São Paulo, 1989.

LAFER, Celso (org.). Esboço de figura. Homenagem a Antonio Candido. São Paulo: Duas Cidades, 1979.

LOPEZ, Telê Ancona. A literatura como direito. Literatura e sociedade. FFLCH-Departamento de Teoria Literária e Literatura Comparada - USP, São Paulo, n. 11, p. 216-219, 2009.

MOURÃO, Rui. Estruturas. Ensaio sobre o romance de Graciliano. Belo Horizonte: Tendência, 1969.

NIETZSCHE, Friedrich. Más allá del bien y del mal. Tradução Andrés Sánchez Pascual. Madrid: Alianza, 1972.

ORDINE, Nuccio. A utilidade do inútil - um manifesto. Tradução Luiz Carlos Bombassaro. Rio de Janeiro: Zahar, 2016.

SCHWARZ, Roberto. Pressupostos, salvo engano, de 'Dialética da Malandragem'. In: Que horas são? São Paulo: Companhia das Letras, 1987.

TODOROV, Tzvetan. A literatura em perigo. Tradução Caio Meira. 3. ed. Rio de Janeiro: Difel, 2010. 
VILLELA-PETIT, Maria da Penha. Platão e a poesia na República. Kriterion, Belo Horizonte, v. 44, n. 107, p. 51-71, Jun/2003. Disponível em acesso de 27 mar. 2017: $<$ scielo.br/scielo.php?pid=S0100-512X2003000100005\&script $=$ sci_abstract\&tlng $=$ pt $>$.

WAIZBORT, Leopoldo. A passagem do três ao um: crítica literária, sociologia, filologia. São Paulo: Cosac Naify, 2007. 